\title{
Construcción de argumentos durante la producción de textos digitales*
}

\section{Construction of Arguments for Digital Texts Production}

\section{Gerzon Yaír Calle Álvarez}

Referencia para citar este artículo: CALLE ÁLVAREZ, G.Y. (2013). "Construcción de argumentos durante la producción de textos digitales".

En: Revista Guillermo de Ockham 11(2). pp. 101-114.

\section{Resumen}

Este artículo es el producto de una investigación que tuvo dentro de sus objetivos fortalecer el pensamiento crítico durante la escritura de textos digitales en ambientes de aprendizaje apoyados por herramientas de la web 2.0 en estudiantes de educación media, cuyos resultados concernientes a la habilidad de construcción de argumentos durante la producción de textos digitales están consignados igualmente en el presente escrito. El enfoque asumido en el estudio fue mixto y en él participaron treinta y dos estudiantes de grado once, quienes durante once sesiones elaboraron producciones escritas digitales que evidenciaran procesos de argumentación. Los resultados mostraron que es posible fortalecer la construcción de argumentos en las prácticas de escritura digital.

Palabras clave: aprendizaje, argumentación, enseñanza, escritura, TIC.

\section{Abstract}

This article is the outcome of a research work which aims to strengthen critical thinking skills when writing digital texts under learning environments supported by Web 2.0 tools in middle school students. We show the results of argument construction skills in the production of digital texts. This is a mixed study that involved 32 students in eleventh grade, who developed digital written productions supported by Web 2.0 tools in 11 sessions within a learning environment. The main results showed that it is possible to strengthen the construction of arguments in digital writing practices.

Keywords: learning, argument, teaching, writing, ICT.

\section{Introducción}

La presente investigación partió de tres retos que se ha impuesto la educación para dar respuesta

- Fecha de recepción del artículo: 07-07-2013 • Fecha de aceptación: 06-09-2013

GERZON YAíR CALLE ÁLVAREZ. Licenciado en Español y Literatura, Magíster en Educación de la Universidad de Antioquia. Profesor de cátedra e integrante del grupo de investigación "Didáctica y nuevas tecnologías” de Universidad de Antioquia. Correo electrónico: pensamientoyescritura@gmail.com.

* Reporte de caso derivado del proyecto "Las habilidades del pensamiento crítico asociadas a la escritura digital en ambientes de aprendizajes apoyados por herramientas del Web 2.0" del Grupo de Investigación “Didáctica y Nuevas Tecnologías” de la Universidad de Antioquia. Código Colciencias COL0003561. Fecha de inicio: junio 2011. Fecha de finalización: junio 2012. 
a las necesidades de una sociedad global como la actual. El primero de ellos es la formación de estudiantes pensadores y críticos, momento en el cual se incorporan las herramientas para elaborar argumentos; o, como afirma Wacquant (2005), los medios para pensar el mundo tal como es y cómo podría ser. El segundo, la incorporación de las Tecnologías de la Información y la Comunicación (TIC) en la educación sobre la base de que no se trata de llevar recursos digitales para continuar con las mismas prácticas tradicionales, sino de la posibilidad de diseñar ambientes de aprendizaje apoyados por estas tecnologías que respondan a los requerimientos de una comunidad educativa específica. El tercero, los procesos de escritura que con el auge de las TIC no aluden solamente a la escritura análoga, sino también a todas las posibilidades que concurren con la producción de textos digitales. Las relaciones que se tejen dentro de estos retos permitieron que durante la ejecución de este proyecto se buscara la manera fortalecer la habilidad para trazar argumentos durante la producción de textos digitales en estudiantes de educación media aportar así a la comprensión de los procesos de escritura.

Dentro de las habilidades del pensamiento crítico se encuentra la elaboración de argumentos (Kunh 1999, Facione, 2000, Fisher, 2001, Halpern, 2006, Guiller et al., 2008) y para esta investigación se tomó esta habilidad orientada a descomponer las situaciones para identificar, presentar y evaluar los argumentos que se presentan dentro de una de ellas. En este proceso, el estudiante debió identificar su posición, reconocer la audiencia, presentar hechos o datos verificables, justificar sus ideas, tener presente la contraparte e indagar sobre el tema, entre otras acciones. La construcción de argumentos puede llegar a persuadir a otro, hacer que comprenda una posición y generar inquietudes, así como dar la posibilidad de autoevaluar los propios planteamientos.

Se toma la escritura digital de manera englobante y se agrupan conceptos como escritura hipermedial, electrónica e hipertextual, entre otras. Se reconoce el funcionamiento del código y los símbolos en los espacios digitales, se muestra la evolución que han tenido en diferentes contextos de escritura y se identifican la imagen y los enlaces dentro de la escritura digital como elementos en la construcción de significado.
Por otra parte, los ambientes de aprendizaje se diseñan para crear condiciones pedagógicas que lo favorezcan y respondan a las necesidades del contexto educativo donde los profesores y estudiantes siguen siendo partícipes, el primero como orientador y el segundo como sujeto activo de su propio aprendizaje. Por lo anterior, dentro de las dinámicas de la presente investigación se diseñó un ambiente de aprendizaje apoyado por herramientas de la web 2.0, en el cual los estudiantes experimentaban con la escritura digital y desarrollaban la habilidad de construcción de argumentos.

\section{Argumentación y TIC}

Entre el pensamiento y el lenguaje se puede plantear una relación dialéctica la cual se va especializando en la medida en que los seres humanos crecen. Ello se puede evidenciar en los procesos comunicativos, cognitivos y sociales en los cuales el individuo va desarrollando habilidades que lo facultan a través del lenguaje y el pensamiento para solucionar conflictos, tomar decisiones, debatir, razonar, preguntar y argumentar. No obstante, como afirma Vigostky (1964) el significado de la palabra es la unidad de ambas funciones del lenguaje en la misma medida en que es unidad del pensamiento.

Todos los seres humanos piensan, pero no lo hacen en el vacío. Siempre habrá una asociación del pensamiento con una idea y esta se puede presentar en forma de texto; sin embargo, muchos de los pensamientos que se producen se desarrollan de manera aislada, distorsionada y sin claridad. Por ello, cuando se genera el pensamiento los individuos pueden aplicar una serie de habilidades para convertir esas ideas sin conexión en una serie de textos con sentido reflexivo que reflejen procesos de pensamiento crítico. El uso que se le dé al lenguaje es importante para la construcción de argumentos; igualmente, las relaciones entre aquel y el pensamiento se ve proyectadas en los procesos de elaboración de significados en los cuales la selección de palabras, imágenes y sonidos puede llevar al reconocimiento de la verdad, a la ejemplificación, a la argumentación y a conclusiones; o por el contrario, suscitar confusiones, falacias, engaños, dudas e incertidumbres. 
Monzón (2010) llevó a cabo una investigación sobre el blog y el desarrollo de habilidades de argumentación y trabajo colaborativo en dos grupos de estudiantes de un colegio privado en la asignatura de ética cuyas conclusiones son las siguientes: 1) el uso del blog en el aula puede ser un recurso para el desarrollo de las habilidades argumentativas en los estudiantes; y 2) el uso de TIC requiere constantes revisiones de la realidad de la institución y de los papeles que cumplen los profesores y estudiantes. Lo anterior sirve de apoyo a la idea de que en la escuela las TIC les abren una puerta al mundo a los estudiantes -quienes ya no se limitan a lo que dice exclusivamente el profesor-, a su escuela y a su territorio cercano. Al hacer parte de un mundo globalizado, los educandos pueden analizar la información que los profesores les brindan, cuestionarla, confrontar las fuentes y comprobar los datos, todo lo cual evidencia un avance del estudiante hacia la construcción de argumentos, sin dejar de lado el hecho de que son consumidores insaciables de información a través de la televisión, la radio y los dispositivos móviles, la cual deben seleccionar, clasificar e interpretar a fin de actualizar sus referentes.

Schwarz y de Groot (2007) desarrollaron una investigación para evaluar un programa fundamentado en el dialogismo y el uso de herramientas para graficar y desplegar la argumentación en debates electrónicos. El estudio se llevó a cabo en una ciudad israelí dentro de una clase de historia, con diez estudiantes de grado noveno y tuvo una duración de siete meses. Para ello el profesor diseñó una serie de actividades con apoyo del programa Dígalo cuyo propósito era generar ideas alrededor de la temática "la infancia y la guerra" y al final una de las conclusiones apuntó a que el uso de dígalo en la discusión permitió evidenciar y fortalecer habilidades argumentativas como la generación de demandas y razones.

En una sociedad que a lo largo de su historia se ha visto afectada por decisiones poco acertadas de sus líderes y ciudadanos, por el deterioro de los valores humanos y por la prevalencia de la opinión subjetiva sobre la razón, el fortalecimiento de la construcción de argumentos se convierte en una herramienta para formar ciudadanos competentes que respondan a las necesidades actuales de un mundo en constate transformación. Formar a los estudiantes para la ciudadanía significa apuntar a la formación de personas capaces de argumentar, tomar decisiones, evaluar las situaciones y autorregularse. Como afirma Reygadas (2005):

Hoy, en tiempos de guerras absurdas, de inventos que no miden las consecuencias sobre el ambiente y la salud, de profundización de las desigualdades a escala mundial, se nos plantea como una urgencia el saber argumentar en todos los ámbitos a favor de la democracia, de la construcción de una ciudadanía crítica y de la supervivencia de la comunidad mundial (p. 14).

Scheuer, Loll, Pinkwart y McLaren (2010) hicieron una revisión de la literatura de los últimos veinte años sobre la argumentación colaborativa o individual asistida por computador, para lo cual tuvieron presente los paradigmas de representación de argumentos que se han utilizado, los diseños de interacción y las cuestiones de arquitectura de software, amén de un análisis de los procesos automáticos para determinar la calidad de los argumentos y retroalimentar al productor, así como la revisión de múltiples estudios que han evaluado el efecto de los diagramas de la argumentación. Sus conclusiones apuntan a que el diseño de una herramienta tecnológica no es el único factor que pesa a la hora de determinar si un sistema de argumentación educativa es efectivo. Se hace necesario dimensionar todo el engranaje educativo, a saber, la secuenciación de las actividades, la distribución de funciones, las instrucciones sobre cómo utilizar las herramientas de diagramación, el uso de herramientas de comunicación externa, y el diseño de la colaboración.

Con el apoyo de las TIC los estudiantes pueden publicar y ser leídos por otros y no limitarse a ser solo consumidores de información, sino ser productores de conocimiento. Un educando puede participar en un foro mundial, crear su texto audiovisual y publicarlo en un canal de videos y diseñar su propia wiki. Para ello necesita tener información acerca del tema, procesar la información, determinar un punto de vista, construir argumentos, plantear conclusiones, buscar información y analizar y comprender otros autores; es decir, desarrollar y aplicar unas habilidades del pensamiento en un entorno digital con base en los recursos de la escritura digital. Cuando un profesor solicita a sus alumnos que participen en una discusión en línea, espera que comprendan que su producción deja de ser una mera tarea 
para convertirse en una publicación global que será leída por ciudadanos de todo mundo. Al contribuir a un entorno de la web el ejercicio de escritura adquiere otro sentido.

\section{Metodología}

La investigación en educación busca la interpretación y profundización de los fenómenos educativos con el propósito de aumentar la comprensión de la realidad circundante de los procesos formativos y el desarrollo integral de los sujetos. El enfoque asumido del presente estudio es mixto y se desarrolló en una comunidad educativa de la ciudad de Medellín con treinta y dos estudiantes de grado once, repartidos en cuatro mujeres y veintiocho hombres, pertenecientes a los estratos dos y tres y adscritos a la media técnica en programación. Las sesiones de trabajo se desarrollaron en una sala de informática con acceso a internet y se llevó a cabo en cuatro fases: 1) Revisión del proyecto de investigación a partir de los referentes de la Institución; 2) Diseño del ambiente de aprendizaje e instrumentos; 3) Desarrollo del ambiente de aprendizaje, observación y pruebas; 4) Análisis de la información, interpretación y validación de datos.

Para el proceso de investigación se diseñó un ambiente de aprendizaje apoyado en herramientas de la Web 2.0: el blog, las redes sociales y el correo electrónico a fin de que los estudiantes aplicaran una serie de acciones que advirtieran de la habilidad de construcción de argumentos. En un periodo de ocho semanas con un promedio de seis horas semanales se desarrollaron las sesiones del ambiente de aprendizaje. Cada semana se generaba una situación de escritura digital en la cual se evidenciara la aplicación de acciones argumentativas orientadas al aprendizaje colaborativo y al uso de las herramientas de la Web 2.0. Durante el proceso el investigador registra sus observaciones y entrevista a los estudiantes acerca de su procedimiento de escritura digital y la aplicación de la habilidad de construcción de argumentos.

Las sesiones de trabajo fueron dieciséis y se distribuyeron de la siguiente forma:

\begin{tabular}{|l|l|}
\hline Sesión & Actividad \\
\hline 1 & Presentación de los integrantes. \\
\hline 2 & Presentación del proyecto. \\
\hline 3 y 4 & Construcción de acuerdos de convivencia \\
\hline 5 & Conocimientos previos. Autorregistro \\
\hline $6,7,8$ y 9 & Producción texto audiovisual \\
\hline 10,11 y 12 & Producción textual. \\
\hline 13,14 y 15 & Producción texto multimodal \\
\hline 16 & Evaluación de cierre. Autorregistro \\
\hline
\end{tabular}

Para la recolección de la información se diseñaron tres instrumentos los cuales se describen a continuación:

1. Escala de observación. Esta era diligenciada por el investigador durante todas las sesiones y se aplicaba a ocho o diez estudiantes por sesión. Finalmente, se observó a cada uno de los estudiantes durante cinco ocasiones con la finalidad de reconocer las acciones que los estos aplicaban para la construcción de argumentos durante los procesos de escritura en espacios de la Web 2.0.

Las operaciones observadas fueron las siguientes:

a. Busca información en diversas fuentes digitales o impresas (páginas web, blogs, wikis, videos, emisoras digitales, libros y periódicos, entre otras fuentes) para elaborar los argumentos.

b. Prepara borradores antes de plasmar sus argumentos.

c. Involucra elementos de representación gráfica (negrilla, cursivas, tamaño, ubicación, color de letra) para trazar los argumentos frente a la posición planteada.

d. Cambia el orden de los argumentos.

e. Incorpora enlaces de contenidos de distintas fuentes (libros, periódicos, videos, canciones, páginas de internet) para construir los argumentos.

f. Involucra algún modo de representación visual o auditiva para construir los argumentos frente a la posición planteada.

g. Lee la formulación inicial de la posición establecida para desarrollar el argumento. 
f. Elabora un diagrama del argumento según las características del medio de publicación (wiki, blog, canal de videos, podcast).

2. Autorregistro. Para la aplicación de este instrumento se diseñó una situación de escritura digital y posteriormente cada estudiante autoevaluaba el proceso a partir del contexto trabajado. El instrumento se aplicó antes y después de implementar el ambiente de aprendizaje e indagaba la frecuencia de uso de cada indicador (siempre, algunas veces, nunca) y el nivel de dificultad en la aplicación de cada una de las acciones en una situación de escritura digital (fácil, difícil, no sé). Para el análisis de los datos de frecuencia y dificultad se utilizó una prueba $t$-student y se procesaron en el paquete estadístico SPSS con el fin de identificar si se presenta un avance entre la aplicación inicial y la final. Igualmente, se aplicó una Anova para registrar las relaciones entre la frecuencia y la dificultad.

Los indicadores que los estudiantes debían autoevaluar fueron los siguientes:

a. Comprendo que los conceptos presentados en los entornos de la web son útiles para dar razones.

b. Encuentro semejanzas en un conjunto de hechos (evento deportivo, noticias, momento histórico, descubrimiento científico) con mi posición y las utilizo en la construcción de mis argumentos.

c. Busco información en diversas fuentes digitales o impresas (páginas web, blogs, wikis, videos, emisoras digitales, libros y periódicos, entre otras) para validar, precisar o apoyar mis argumentos.

d. Elaboro borradores antes de plasmar mis argumentos.

e. Involucro elementos de representación gráfica (negrilla, cursivas, tamaño, ubicación, color de letra) para construir mis argumentos.

f. Evalúo los pros y los contras de una situación para delimitar mis argumentos.

g. Incorporo enlaces de contenidos de distintas fuentes (libros, periódicos, videos, canciones, páginas de internet) para construir mis argumentos.

h. Utilizo la imagen o el sonido en la producción de los argumentos.

i. Reviso mi planteamiento inicial para identificar las relaciones con los argumentos desarrollados.

j. Elaboro un diagrama del argumento según las características del medio de publicación (wiki, blog, canal de videos, podcast).

3. Entrevista semipautada. Después de cada sesión se entrevista a tres o cuatro estudiantes observados anteriormente sobre el desarrollo de la sesión y las decisiones que tomaron en el proceso de escritura de los argumentos. Las preguntas generadoras eran las siguientes:

- ¿Qué dificultades encuentra al momento de escribir apoyado en herramientas de la web 2.0 ?

- ¿Cómo supera las dificultades?

- ¿Qué herramientas de internet se usaron para construir los argumentos? ¿Por qué?

- ¿Cuáles son los recursos de internet que más utilizó para escribir? ¿Por qué?

- ¿Qué es lo que más le ha gustado de las sesiones de trabajo?

- ¿Qué es lo que menos le ha gustado de las sesiones de trabajo?

El análisis de los datos cualitativos comporta la segmentación de un texto en elementos con significado dentro del proceso de indagación. Para la investigación se procedió inductivamente sin restar importancia al pensamiento de los estudiantes. Cada una de las respuestas a las preguntas de la entrevista semipautada se descompuso en expresiones relacionadas con un asunto determinado alusivas a un concepto que guardaba relación con la temática de la investigación. Las unidades de análisis podían consistir en palabras, símbolos o proposiciones semánticas con un sentido propio. Las respuestas de los estudiantes generaron entramados de relación entre códigos que fueron graficados como mapas de relación en Atlas-ti. En la investigación se optó por una vía inductiva para el análisis, es decir, a 
partir de los códigos obtenidos en las respuestas de los estudiantes se crearon por similitud conceptual las correspondientes categorías y subcategorías.

\section{Resultados}

La presentación y el análisis de los resultados se desarrolla de la siguiente forma: primero, se presentan los resultados de la escala de observación; segundo, se muestran los resultados del autorregistro para lo cual se retoman los resultados de la aplicación inicial y final; tercero, se exponen las categorías que emergieron de las entrevistas semipautadas; cuarto, se presenta una triangulación de los resultados y se advierte la relación entre su operación y el fortalecimiento de la habilidad para construir argumentos durante la producción de textos digitales.

\section{Funcionamiento para la habilidad de construcción de argumentos}

La primera impresión de los estudiantes frente a la habilidad de construcción de argumentos fue la dificultad que implica argumentar. A pesar de haber tenido experiencias poco exitosas en otras áreas del conocimiento en las cuales les habían asignado una tarea con este enfoque, en el trascurso de las sesiones del ambiente de aprendizaje fueron descubriendo herramientas que les permitían elaborar argumentos que sustentaban su posición.

Para el análisis de la habilidad de construcción de argumentos se sumaron cada una de las evidencias de aplicación de las acciones por parte de los estudiantes. El máximo posible entre las relaciones de las aplicaciones y no aplicaciones de las acciones era de treinta y dos por cada una de las sesiones, es decir, el equivalente al número de estudiantes participantes. Posteriormente, se llevó a cabo un examen de las dinámicas entre las sesiones cuyos resultados y análisis de cada una de las acciones durante las sesiones de implementación del ambiente de aprendizaje se presentan a continuación.

La acción "Busca información en diversas fuentes digitales o impresas (páginas web, blogs, wikis, videos, emisoras digitales, libros, periódicos, entre otras) para construir los argumentos" fue una de las más utilizadas al momento de elaborar los argumentos y entre ellas las más recurridas fueron los espacios de discusión como blog y foros. Durante las cinco sesiones, los estudiantes se valieron de manera recurrente de la acción para la construcción de los argumentos, lo cual se puede observar en la Tabla 1. La dinámica de esta acción hizo posible evidenciar que los estudiantes la utilizan como herramienta para identificar recursos que sustenten sus ideas.

Tabla 1

Resultados aplicación acción 1

\begin{tabular}{|c|c|c|c|c|c|c|}
\hline \multicolumn{2}{|c|}{ Acción 1} & $\begin{array}{c}\text { Sesión } \\
1 \\
\end{array}$ & $\begin{array}{c}\text { Sesión } \\
2 \\
\end{array}$ & $\begin{array}{c}\text { Sesión } \\
3 \\
\end{array}$ & $\begin{array}{c}\text { Sesión } \\
4 \\
\end{array}$ & $\begin{array}{c}\text { Sesión } \\
5\end{array}$ \\
\hline \multirow[t]{3}{*}{ Validación } & $\begin{array}{c}0 \\
\text { (no aplicación) }\end{array}$ & 1 & 0 & 3 & 1 & 0 \\
\hline & 1 (aplicación) & 31 & 32 & 29 & 31 & 32 \\
\hline & Total & 32 & 32 & 32 & 32 & 32 \\
\hline
\end{tabular}

La acción "Elabora borradores antes de plasmar sus argumentos" presentó un aumento significativo entre la primera sesión y las cuatro siguientes (Tabla 2) en virtud a que reconocieron las posibilidades que les brindan las herramientas digitales para elaborar borradores que pueden ser editados y mejorados antes de incorporarlos al texto final. Una práctica constante fue utilizar las herramientas de Googledocs para redactar los borradores de los argumentos a la vez que los compartían con los compañeros para que los revisaran o complementaran; igualmente, la herramienta les permitía identificar los cambios aplicados al argumento. El desarrollo de la acción se emprendió con una aplicación mínima por parte de algunos estudiantes; sin embargo, con el apoyo de las herramientas de la web tomó fuerzas en las sesiones dos, tres y cuatro, aunque en la quinta disminuyó su uso quizá debido a que el texto que desarrollaron tenía que ver con el de la primera sesión y los estudiantes consideraron el primero como el borrador a fin de mejorarlo y con los ajustes pertinentes convertirlo en el texto cinco.

Tabla 2

Resultados aplicación acción 2

\begin{tabular}{cccccccc}
\hline \multirow{2}{*}{ Acción 2 } & Sesión & Sesión & Sesión & Sesión & Sesión \\
Validación & 1 & 2 & 3 & 4 & 5 \\
\cline { 2 - 7 } & $\begin{array}{c}0 \\
\text { (no aplicación) }\end{array}$ & 25 & 10 & 5 & 3 & 15 \\
\cline { 2 - 7 } & 1 (aplicación) & 7 & 22 & 27 & 29 & 17 \\
\cline { 2 - 7 } & Total & 32 & 32 & 32 & 32 & 32 \\
\hline
\end{tabular}

La acción "Incorpora enlaces de contenidos de distintas fuentes (libros, periódicos, videos, canciones, páginas de internet) para construir los argumentos" tomó importancia entre los estudian- 
tes en la sesiones en las cuales el trabajo se hizo con base en el texto audiovisual, el documento en Googledocs y la presentación en la misma plataforma. Ello se debió a que descubrieron que los enlaces les permitían ejemplificar, precisar, sustentar sus ideas y elaborar un argumento con fuerza dentro de la estructura global del texto (Tabla 3). Los enlaces le aportaban una mirada no lineal del texto facultando con ello el desarrollo de una lógica no secuencial que conecta diversas miradas y puntos de anclaje que podían complementar, estar a favor o en contra de la posición de los estudiantes. El desarrollo de la acción da cuenta de cómo la finalidad y el formato del texto median en las decisiones que los estudiantes toman al momento de la producción de un texto.

Tabla 3

Resultados aplicación acción 3

\begin{tabular}{|c|c|c|c|c|c|c|}
\hline \multicolumn{2}{|c|}{ Acción 3} & Sesión & Sesión & Sesión & Sesión & Sesión \\
\hline \multirow[t]{3}{*}{ Validación } & $\begin{array}{c}0 \\
\text { (no aplicación) }\end{array}$ & 28 & 9 & 13 & 20 & 0 \\
\hline & 1 (aplicación) & 4 & 23 & 19 & 12 & 32 \\
\hline & Total & 32 & 32 & 32 & 32 & 32 \\
\hline
\end{tabular}

La acción "Involucra elementos de representación gráfica (negrilla, cursivas, tamaña, ubicación, color de letra) para construir los argumentos frente a la posición planteada" acción tomó mucha fuerza durante la producción del texto multimodal (afiche digital, sesión 4), lo cual se puede observar en la Tabla 4. Ello se explica en el hecho de que uno de los retos de la producción de argumentos con base en una única mirada, implica que cada palabra o imagen debe aportar a la semántica global del texto. El uso de negrilla o de color para resaltar las palabras en las que el estudiante quería hacer énfasis fue significativo en las sesiones dos, cuatro y cinco. Los educandos reconocieron que en la dinámica de la escritura digital el formato de la letra aporta al significado del texto y a la impresión o comprensión del lector sobre la producción digital. La dinámica de la acción se caracterizó por una variedad entre las sesiones; la mayor aplicación se dio en la sesión cuatro y la menor en la sesión uno.

Tabla 4

Resultados aplicación acción 4

\begin{tabular}{|c|c|c|c|c|c|c|}
\hline \multicolumn{2}{|c|}{ Acción 4} & Sesión & Sesión & Sesión & Sesión & Sesión \\
\hline \multirow[t]{3}{*}{ Validación } & $\begin{array}{c}0 \\
\text { (no aplicación) }\end{array}$ & 24 & 6 & 17 & 0 & 12 \\
\hline & 1 (aplicación) & 8 & 26 & 15 & 32 & 20 \\
\hline & Total & 32 & 32 & 32 & 32 & 32 \\
\hline
\end{tabular}

La acción "Involucra algún modo de representación visual o auditiva para construir los argumentos frente a la posición planteada" se puede considerar como uno de los descubrimientos que los estudiantes llevaron a cabo para fortalecer y desarrollar la habilidad de la construcción de argumentos. En la primera sesión, consideraban un argumento como algo que solo se podía presentar con el alfabeto $y$ que no permitía otra forma ya que perdía toda validez; sin embargo, a partir de las orientaciones dadas en el ambiente de aprendizaje redescubrieron la forma de argumentar, el sonido tomó fuerza en la sesión dos durante la producción del texto audiovisual y la imagen en las sesiones dos, tres, cuatro y cinco. Adriessen (2006) afirma que la argumentación implica la elaboración, el razonamiento y la reflexión. Los estudiantes reconocieron en la imagen y el sonido factores para construir sus argumentos (Tabla 5). La dinámica de la acción presentó una variedad entre la primera sesión y las demás: mientras en la primera su aplicación fue mínima, a partir de la sesión dos esta aumentó su representatividad dentro de la habilidad construcción de argumentos.

Tabla 5

Resultados aplicación acción 5

\begin{tabular}{cccccccc}
\hline \multirow{2}{*}{ Acción 5 } & \multicolumn{2}{c}{ Sesión } & Sesión & Sesión & Sesión & Sesión \\
Validación & 0 & 1 & 2 & 3 & 4 & 5 \\
\cline { 2 - 7 } & \begin{tabular}{c} 
(no aplicación) \\
\cline { 2 - 7 }
\end{tabular} & 26 & 0 & 3 & 5 & 8 \\
\cline { 2 - 7 } (aplicación) & 6 & 32 & 29 & 27 & 24 \\
\cline { 2 - 7 } & Total & 32 & 32 & 32 & 32 & 32 \\
\hline
\end{tabular}

La acción "Lee la formulación inicial de la posición planteada para desarrollar el argumento" fue aplicada en diferentes momentos como estrategia de verificación entre el establecimiento de la posición frente al tema y el desarrollo del texto. Se caracterizó por no ser un fuerte en la construcción de argumentos pero sí para mantener la línea temática; sin embargo, influyó en la calidad argumental (ver Tabla 6). La dinámica de la acción se distinguió por ser igualada su aplicación y no aplicación en la primera sesión; en la sesión tres ello se reflejó significativamente debido a que el tipo de texto por elaborar era un documento en Googledocs, lo cual implicaba revisar permanentemente la coherencia en el texto. 
Tabla 6

Resultados aplicación acción 6

\begin{tabular}{cccccccc}
\hline \multirow{2}{*}{ Acción 6 } & Sesión & Sesión & Sesión & Sesión & Sesión \\
Validación & $\begin{array}{c}0 \\
\text { (no aplicación) }\end{array}$ & 16 & 15 & 6 & 14 & 11 \\
\cline { 2 - 7 } & 1 (aplicación) & 16 & 17 & 26 & 18 & 21 \\
\cline { 2 - 7 } & Total & 32 & 32 & 32 & 32 & 32 \\
\hline
\end{tabular}

La acción "Cambia el orden de los argumentos" adquirió reconocimiento en la última sesión. La mayoría de los estudiantes partieron de la producción elaborada en la primera sesión para confeccionar el último texto; sin embargo, reconocieron que al diseño de los argumentos le faltaba fuerza y ello implicó que su orden fuera modificado según la importancia dentro del texto. Posteriormente fueron desarrollados acorde con el establecimiento de la posición frente al tema. Durante la acción de cambio de orden los alumnos debían tener claro el proceso reflexivo en el que se desarrolla la argumentación y reafirmar, refutar, ejemplificar o aplicar la posición inicial (ver Tabla 7). La dinámica de la acción que cambia el orden de los argumentos tuvo aplicaciones mayores en las sesiones dos y cinco; en las sesiones tres y cuatro fue poca su aplicación.

Tabla 7

Resultados aplicación acción 7

\begin{tabular}{cccccccc}
\hline \multirow{2}{*}{ Acción 7 } & Sesión & Sesión & Sesión & Sesión & Sesión \\
Validación & $\begin{array}{c}0 \\
\text { (no aplicación) }\end{array}$ & 16 & 12 & 20 & 18 & 0 \\
\cline { 2 - 7 } & 1 (aplicación) & 16 & 20 & 12 & 14 & 32 \\
\cline { 2 - 7 } & Total & 32 & 32 & 32 & 32 & 32 \\
\hline
\end{tabular}

La acción "Elabora un diagrama del argumento según las características del medio de publicación (wiki, blog, canal de videos, podcast)" no tuvo mayor implicación en la construcción de los argumentos; solamente en la sesión tres su aplicación fue mayor. Los estudiantes edificaron los argumentos y mantuvieron coherencia con la línea temática del texto, pero desconocían los requisitos para poder publicarlo en una de las herramientas de la web. Eso se puede observar porque en su producción inicial algunos textos mantenían una estructura coherente; sin embargo, cuando se publicaban en el blog perdían esa uniformidad o no se visualizaba, empero los estudiantes consideraban que esta acción no repercutía en la calidad de los argumentos (ver Tabla 8). El desarrollo de la acción en las sesiones uno, dos, cuatro y cinco se caracterizó por ser mayor la no aplicación durante la construcción de los argumentos, solamente en la sesión tres su aplicación fue mayor; sin embargo, no repercutió en las demás sesiones.

Tabla 8

Resultados aplicación acción 8

\begin{tabular}{|c|c|c|c|c|c|c|}
\hline \multicolumn{2}{|c|}{ Acción 8} & Sesión & Sesión & Sesión & Sesión & $\begin{array}{c}\text { Sesión } \\
5\end{array}$ \\
\hline \multirow[t]{3}{*}{ Validación } & $\begin{array}{c}0 \\
\text { (no aplicación)) }\end{array}$ & 32 & 28 & 3 & 17 & 21 \\
\hline & 1 (aplicación) & 0 & 4 & 29 & 15 & 11 \\
\hline & Total & 32 & 32 & 32 & 32 & 32 \\
\hline
\end{tabular}

\section{Autorregistro. Habilidad para la construcción de argumentos}

Para fortalecer la habilidad de la construcción de argumentos se les presentaba a los estudiantes ejemplos de cómo se podía argumentar. Por su parte, el profesor erigió argumentos utilizando recursos de la Web 2.0 y llevó a cabo lecturas de ensayos sobre diversos contenidos. Desde las aplicaciones iniciales los estudiantes manifestaron las dificultades para la construcción de argumentos; sin embargo, fueron descubriendo que para hacerlo era necesario sustentar las posiciones con explicaciones, ejemplos o casos y desarrollar justificaciones que permitieran comprobar o rechazar los planteamientos en discusión. Comprendieron que las imágenes, los esquemas, los gráficos, los sonidos y los enlaces servían para dar razones, justificar o ampliar la temática dentro del marco del argumento.

A continuación se presenta la Tabla 9 en la cual se muestran los resultados de la sumatoria de las acciones de cada una de las aplicaciones.

En la frecuencia de uso de las acciones para la habilidad de construcción de argumentos se observa que las acciones 1 y 4 permanecieron igual y en las acciones 2, 3, 5, 6, 7, 8, 9 y 10 esta frecuencia fue mayor. Ello es un ejemplo fehaciente de que los estudiantes aplicaron una serie de acciones con el propósito de mejorar sus producciones para lo cual combinaban información anterior con nuevos conceptos, reconocían que la carencia de justificaciones derivaba en ideas inequívocas, que se podía suprimir las repeticiones sobre las mismas ideas y propugnaban la importancia de mantener una coherencia entre los enlaces y el texto base. Sin embargo, las mayores diferencia se dieron en las acciones 3, 7, 10, correspondientes a la elaboración 


\section{Tabla 9}

Comparación de las acciones en frecuencia y dificultad según aplicación inicial y final para la habilidad construcción de argumentos

\begin{tabular}{|c|c|c|c|c|c|c|c|}
\hline \multirow[b]{2}{*}{ Habilidad } & \multirow[b]{2}{*}{ Acciones } & \multicolumn{3}{|c|}{ Frecuencia } & \multicolumn{3}{|c|}{ Dificultad } \\
\hline & & Inicial & Final & $\begin{array}{c}\text { Resultado } \\
\text { final frente } \\
\text { al inicial }\end{array}$ & Inicial & Final & $\begin{array}{l}\text { Resultado } \\
\text { final frente } \\
\text { al inicial }\end{array}$ \\
\hline \multirow{10}{*}{ 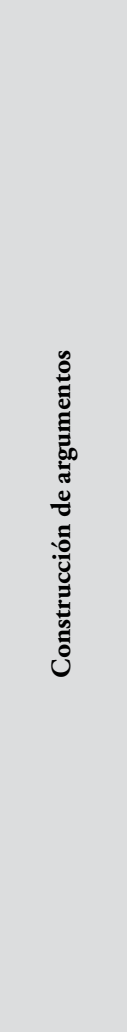 } & $\begin{array}{l}\text { 1. Comprendo que los conceptos presen- } \\
\text { tados en los entornos de la web me sirven } \\
\text { para dar razones. }\end{array}$ & 50 & 50 & Igual & 48 & 50 & Mayor \\
\hline & $\begin{array}{l}\text { 2. Busco información en diversas fuentes } \\
\text { digitales o impresas (páginas web, blogs, } \\
\text { wikis, videos, emisoras digitales, libros, pe- } \\
\text { riódicos, entre otras) para validar, precisar o } \\
\text { apoyar mis argumentos. }\end{array}$ & 57 & 59 & Mayor & 57 & 62 & Mayor \\
\hline & $\begin{array}{l}\text { 3. Elaboro borradores antes de plasmar mis } \\
\text { argumentos. }\end{array}$ & 19 & 29 & Mayor & 40 & 43 & Mayor \\
\hline & $\begin{array}{l}\text { 4. Encuentro semejanzas en un conjunto } \\
\text { de hechos (evento deportivo, noticias, } \\
\text { momento histórico, descubrimiento } \\
\text { científico) con mi posición y las utilizo en } \\
\text { la construcción de mis argumentos. }\end{array}$ & 32 & 32 & Igual & 40 & 43 & Mayor \\
\hline & $\begin{array}{l}\text { 5. Involucro elementos de representa- } \\
\text { ción gráfica (negrilla, cursivas, tamańo, } \\
\text { ubicación, color de letra) para construir mis } \\
\text { argumentos. }\end{array}$ & 40 & 42 & Mayor & 56 & 56 & Igual \\
\hline & $\begin{array}{l}\text { 6. Evalúo los pros y los contras de una } \\
\text { situación para delimitar mis argumentos. }\end{array}$ & 30 & 35 & Mayor & 35 & 42 & Mayor \\
\hline & $\begin{array}{l}\text { 7. Incorporo enlaces de contenidos de } \\
\text { distintas fuentes (libros, periódicos, videos, } \\
\text { canciones, páginas de internet) para cons- } \\
\text { truir mis argumentos. }\end{array}$ & 32 & 47 & Mayor & 57 & 55 & Mayor \\
\hline & $\begin{array}{l}\text { 8. Utilizo la imagen o el sonido en la } \\
\text { producción de los argumentos. }\end{array}$ & 28 & 36 & Mayor & 43 & 47 & Mayor \\
\hline & $\begin{array}{l}\text { 9. Reviso mi planteamiento inicial para } \\
\text { identificar las relaciones con los argumentos } \\
\text { desarrollados. }\end{array}$ & 43 & 45 & Mayor & 45 & 53 & Mayor \\
\hline & $\begin{array}{l}\text { 10. Elaboro un diagrama del argumento } \\
\text { según las características del medio de } \\
\text { publicación (wiki, blog, canal de videos, } \\
\text { podcast). }\end{array}$ & 17 & 27 & Mayor & 24 & 30 & Mayor \\
\hline
\end{tabular}

de borradores, incorporación de enlaces para argumentar y elaboración de diagramas del argumento.

Los estadísticos correlacionales mostraron que se da una relación positiva muy significativa entre las aplicaciones inicial y final. El nivel de significancia es de 0.000 para la frecuencia de uso habilidad de construcción de argumentos, lo que advierte que las relaciones dadas entre las aplicaciones mantienen ciertas características que validan el uso y los resultados del instrumento. El grado de confianza para las diferencias entre las medias se estimó con una confianza del $95 \%$. La diferencia entre las medias entre la aplicación inicial y final después de la implementación del ambiente de aprendizaje se encuentra entre $1.7 \mathrm{y}$ 9.1 de frecuencia de uso. El valor del nivel crítico fue 0.009 sobre un nivel de significancia de 0.05 , por lo tanto $0.009<0.05$. Ello permite afirmar que la frecuencia de uso de la habilidad construcción de argumentos difiere entre la aplicación inicial y la aplicación final.

Los niveles de dificultad de la habilidad construcción de argumentos variaron entre la aplicación inicial y la final, como se muestra en la Tabla 9. Para las acciones 1, 2, 3, 4, 6, 7, 8, 9 y 10 el nivel de dificultad disminuyó y para la acción 5 aumentó. Sin embargo, las mayores diferencias se encuentran en las acciones 6 y 9 , lo cual apunta a que los niveles de dificultad disminuyeron para las acciones que están relacionadas con evaluar los pro y los contra de un argumento, revisar el planteamiento inicial y confrontarlo con los argumentos escritos. Los estudiantes reconocieron que las relaciones causa efecto son herramientas que sirven para dar razones, que las ambigüedades en las ideas les resta fuerza a los argumentos y que es importante mantener coherencia entre los planteamientos iniciales y el desarrollo del texto. 
Los estadísticos correlacionales mostraron que hay una relación positiva significativa entre las aplicaciones inicial y final. El nivel de significancia es de 0.000 para los niveles de dificultad de aplicación de la habilidad construcción de argumentos, lo que permite afirmar que las relaciones dadas entre las aplicaciones mantienen ciertas características y ello valida el uso y los resultados del instrumento. El intervalo de confianza para las diferencias entre las medias se estima en $95 \%$ y la diferencia entre las medias entre la aplicación inicial y final después de la implementación del ambiente de aprendizaje se encuentra entre -5.8 y -1.4 de nivel de dificultad. El valor del nivel crítico es de 0.005 sobre un nivel de significancia de 0.05 , por lo tanto $0.005<$ 0.05 . Ello apunta a la conclusión de que los niveles de dificultad de la habilidad de construcción de argumentos difieren entre la aplicación inicial y la aplicación final.

A manera de síntesis, se puede afirmar que la implementación del ambiente de aprendizaje posibilitó el fortalecimiento de la habilidad de construcción de argumentos gracias a que los estudiantes generaban búsquedas en la web y los contenidos seleccionados les servían para cimentar razones. Utilizaban recursos como Googledocs para plasmar sus borradores y los esquemas del argumento que luego utilizaban en la producción final. En los procesos de búsqueda evaluaban los pros y los contras de la información encontrada o producida y la utilización de la imagen, los sonidos y los enlaces para argumentar fueron recurrentes.

\section{Resultados de la entrevista semipautada}

Para el análisis cualitativo se procedió inductivamente sin soslayar el pensamiento de los estudiantes. Las respuestas a las preguntas de la entrevista semipautada se transformaron en expresiones de análisis y generaron entramados de relación entre códigos que fueron graficados como mapas de relación en Atlas-ti. Identificada la expresión y obtenida la unidad de análisis se procedió a codificarla, para lo cual se determinaron las letras en mayúscula para las categorías y los números para las subcategorías. De la categoría de análisis construcción de argumentos emergieron cuarenta y un códigos relacionados con la búsqueda de información, herramientas de la web para presentar argumentos y redacción de argumentos. La Tabla 10 resume las relaciones entre los códigos $\mathrm{y}$ las familias.

En la categoría construcción de argumentos se puede observar que la familia con mayor número de códigos es aquella que tiene que ver con la utilización de herramientas de la web, la cual tiene relacionados veintiún códigos que equivalen al $51.22 \%$ del total de códigos de la categoría. Le siguen la familia asociada a la comprensión de que los conceptos de la web sirven para dar razones (29.27 \%) y las demás familias con un porcentaje por debajo del diez por ciento. Los resultados evidencian que los estudiantes utilizan herramientas de la web para construir sus argumentos

Generar procesos de búsqueda que los remitieran a información sobre la temática desarrollada mediante buscadores como Google y Yahoo, el uso

Tabla 10

Subcategorías de construcción de argumentos

\begin{tabular}{|c|c|c|c|c|c|}
\hline \multicolumn{2}{|c|}{ Categoría } & \multicolumn{2}{|r|}{ Subcategorías } & \multirow{2}{*}{$\begin{array}{l}\text { Número } \\
\text { códigos }\end{array}$} & \multirow[t]{2}{*}{ Porcentaje } \\
\hline Código & Descriptor & Familia & Descriptor & & \\
\hline \multirow{5}{*}{ B } & \multirow{5}{*}{$\begin{array}{l}\text { Construcción de } \\
\text { argumentos }\end{array}$} & 1 & $\begin{array}{l}\text { Búsqueda de información en diversas fuentes digi- } \\
\text { tales o impresas para construir los argumentos. }\end{array}$ & 4 & 9.76 \\
\hline & & 2 & $\begin{array}{l}\text { Utilización de herramientas de la web para cons- } \\
\text { truir argumentos }\end{array}$ & 21 & 51.22 \\
\hline & & 3 & $\begin{array}{l}\text { Comprensión de que los conceptos presentados en } \\
\text { la web sirven para dar razones. }\end{array}$ & 12 & 29.27 \\
\hline & & 4 & $\begin{array}{l}\text { Utilización de algún modo de representación visual } \\
\text { o auditiva para construir los argumentos. }\end{array}$ & 3 & 7.32 \\
\hline & & 5 & $\begin{array}{l}\text { Evaluar los pros y los contras de una situación para } \\
\text { delimitar los argumentos. }\end{array}$ & 1 & 2.44 \\
\hline \multicolumn{4}{|c|}{ Total códigos categoría construcción de argumentos } & 41 & 100 \\
\hline
\end{tabular}


Wikipedia o Word Reference como sitios donde se encuentran conceptos que ayudaban a precisar las ideas, crear enlaces con estos sitios e ingresar a páginas especializadas son acciones que les aportan al desarrollo de los argumentos. Otros trabajos desarrollados sobre el tema contribuyen a la comprensión del propio trabajo y las monografías que se encuentran en la web se convierten en una fuente de consulta. Para discusiones en línea, foros y comentarios de otras personas alrededor del tema que se está abordando, se accede a blogs o a Yahoo respuestas lo cual permite tener una mirada sobre el tema desde la perspectiva de los otros. Los videos sobre el núcleo temático hacen parte de las fuentes de consulta y de ellos se pueden retomar ideas que se desarrollan y se plasman a través de las imágenes.

Al momento de construir los argumentos, herramientas como los traductores son un apoyo para tener referentes de otras culturas sobre la misma problemática. Los programas como Microsoft, Power Point y Prezi se ven como instrumentos que permiten mostrar los argumentos que utilizan diversos recursos visuales e incorporar diversos modos de representación de las ideas. Durante el análisis de la información se encontró que las categorías Búsqueda de información en diversas fuentes digitales o impresas para construir los argumentos y Utilización de herramientas de la web para construir argumentos, se complementan. Los siguientes esquemas grafican las respuestas de los estudiantes frente a estas categorías y en ellos se puede ver las relaciones existentes entre las respuestas de los estudiantes y la categoría:

- El comprender que los conceptos que se presentan en la web sirven para dar razones es un avance en los procesos de construcción de argumentos. Las páginas web se convierten en apoyo para ampliar la información y las fuentes de consulta especializada son referentes confiables, qué duda cabe; pero revisar varias fuentes de información en la web contribuye a fortalecer los argumentos. Los videos y ensayos producidos por otros autores así como las enciclopedias son un referente al momento de sustentar la temática desarrollada. Mediante los buscadores se encuentran páginas web, videos y blogs, que se convierten en soporte, justificaciones y ejemplos de los argumentos
- La imagen y el sonido se convierten en modos dentro del proceso de construcción de los argumentos y el uso de recursos multimedia fortalece la presentación de las ideas sobre la tema. Las herramientas de video mejoran los procesos de producción y programas como Microsoft Power Point permiten integrar en un solo texto videos, esquemas, imágenes y sonidos.

A manera de síntesis se presenta un esquema (Gráfico 1) que permite visualizar cómo operan la habilidad de construcción de argumentos durante la producción de textos digitales.

\section{Conclusiones}

Durante los procesos de escritura digital es posible desarrollar la habilidad de construcción de argumentos. Las imágenes, los sonidos, los enlaces contribuyen para que los argumentos se puedan ejemplificar, precisar, ampliar y sustentar. La argumentación va más allá de utilizar la escritura análoga; se puede hacer uso de todos los recursos que brinda la web y no es necesario construir un argumento de manera lineal. Sin embargo, es importante que cada uno de los elementos involucrados en el argumento aporte al significado del texto.

El uso del blog fue una fortaleza dentro de la investigación. Los estudiantes comprendieron que los procesos de producción no son facultativos del profesor sino de toda la comunidad y ello exigía mayor discernimiento de sus procesos de escritura y responsabilidad al momento de publicar.

Si bien al momento de cerrar la investigación había pocos comentarios en el blog, se observa el aumento de visitas. Churchill (2009) afirma con respecto a los blogs que un profesor puede crear un ambiente de aprendizaje en el que los estudiantes se sientan parte importante de la comunidad de la clase y sus necesidades y opiniones sean reconocidas y tratadas.

El construir argumentos en un entorno digital les brinda a los estudiantes la posibilidad de buscar información para justificar o precisar sus ideas, elaborar esquemas que se pueden convertir en rutas de lectura o escritura, apoyarse en imágenes o sonidos creando así conexiones entre sus pensa- 
Gráfico 1

Operación de la habilidad para construir argumentos

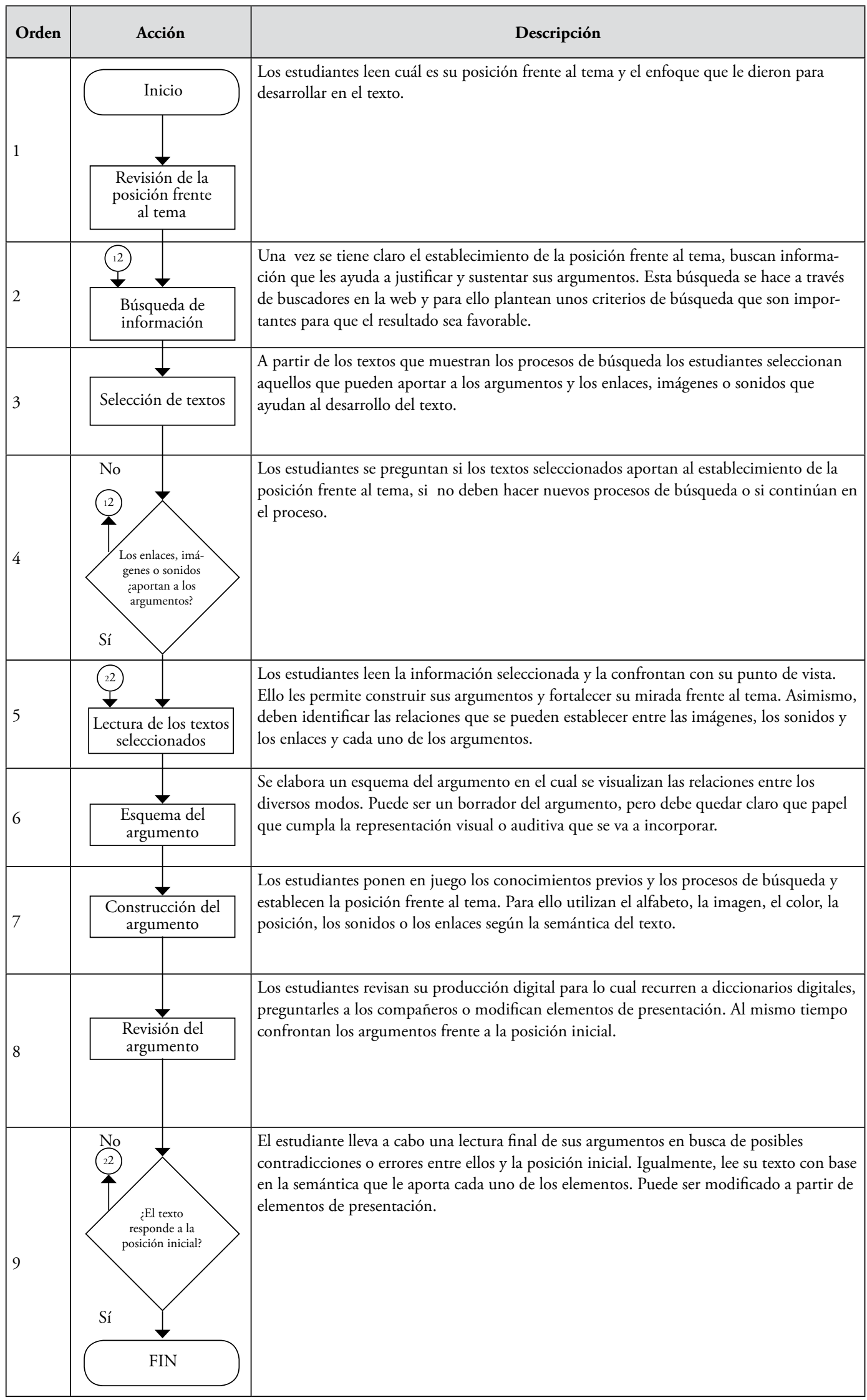


mientos y hacer procesos de revisión y corrección permanentes sin necesidad de reescribir los argumentos. Sin embargo, para desarrollar los procesos de argumentación apoyados con TIC en la escuela es importante que el profesor construya toda una dinámica en su clase a partir de lo didáctico y lo conceptual.

La posibilidad de que los estudiantes utilizaran herramientas digitales para elaborar borradores y graficar los argumentos repercutió en su calidad. Ellos utilizaron procesadores de textos, programas de elaboración de presentaciones o de diagramación para presentar sus ideas, las cuales posteriormente se asociaban al argumento que querían reforzar, precisar o ampliar. Esa acción se observó en cada una de las sesiones y se fue perfeccionando por parte de los estudiantes con el transcurrir de las dinámicas del ambiente de aprendizaje.

Construir argumentos en espacios digitales les permitía revisar permanentemente sus planteamientos iniciales, acción que se evidenciaba cuando deseaban hacer conexiones dentro del mismo texto lo cual les demandaba revisar sus ideas, las relaciones que se habían establecido y cómo se estructuraron las dinámicas de lectura. Los alumnos se apoyaban en sus compañeros para los procesos de revisión, les pedían a otros que los leyeran y hasta creaban espacios de escritura digital compartida para que los demás hicieran los comentarios sobre sus argumentos.

Los estudiantes no solamente aumentaron la frecuencia de uso de las acciones para la construcción de argumentos, sino que también bajaron los niveles de dificultad. A pesar de que siempre afirmaban que argumentar era una situación compleja, encontraron en las herramientas de la Web 2.0 apoyo y recursos para hacerlo. La imagen jugó un papel fundamental al momento de argumentar puesto que no se trataba exclusivamente de la estética de presentación sino de seleccionar y utilizar la imagen adecuada para que por sí misma expresara las propias razones y las justificaciones y expusiera los ejemplos o complementos al contenido del texto.

\section{Bibliografía}

- ANDRIESSEN, J. (2006). Arguing to learn. En K. Sawyer (Ed.) Handbook of the Learning Sciences. Cambridge: Cambridge University Press.

- CHURCHILL, D. (2009). Educational applications of Web 2.0: Using blogs to support teaching and learning. En: British Journal of Educational Technology 40(1). pp. 179-183.

- FACIONE, P.A., Facione N.C. y Giancarlo C.A.F. (2000). The California Critical Thinking Disposition Inventory (CCTDI). Milbrae, California: The Academic Press.

- FISHER, A. (2001) Critical Thinking: An Introduction. Cambridge University Press: Cambridge.

- GUILLER, J., DURNDELl, A. y ROSS, A. (2008). Peer interaction and critical thinking: Face-to-face or online discussion? En: Learning and Instruction 18. pp. 187-200.

- HALPERN, D. (2006). Halpern Critical Thinking Assessment Using Everyday Situations: Background and scoring standards (2o Report). Unpublished manuscript. Claremont, CA: Claremont McKenna College.

- KUHN, D. (1999). A developmental model of critical thinking. En: Educational Researcher 28. pp. 1646. Doi:10.3102/0013189X028002016.

- MONZÁ, L. (2011). El blog y el desarrollo de habilidades de argumentación y trabajo colaborativo. En: Perfiles educativos 33 (131). pp. 80-93.

- REYGADAS, P. (2005). El arte de argumentar. México: UACM-Castellanos Editores.

- SCHEUER, O., LOLL, F y PINKWART, N. MCLAREN, B.M. (2010). Computer supported argumentation: A review of the state of the art. En: Computer-Supported Collaborative Learning 5. pp. 43-102. 
- SCHWARZ B.B. y DE GROOT, R. (2007). Argumentation in a changing world. En: Computer-Supported Collaborative Learning 2. pp. 297-313.

- VIGOSTKY (1964). Pensamiento y Lenguaje. Buenos Aires: Lautaro.

- WACQUANT L. (2005). Entrevista con Loïc Wacquant: Pensamiento crítico y disolución de la Doxa. En: Realidad visual 2. pp. 43-50.

$114<$ Universidad de San Buenaventura, Cali - Colombia 